\title{
Attitudes of Dental Interns Towards Mental Illness
}

\author{
V. Rasmina, Benil Hafeeq, N.A. Uvais*, V.S. Sreeraj
}

\section{Rasmina, Benil Hafeeq, N.A. Uvais*, V.S. Sreeraj}

\begin{abstract}
'Department of Dentistry, Al Sanah dental speciality centre, Calicut, Kerala, INDIA.

${ }^{2}$ Department of Nephrology, laraa International Hospital and Research Centre, Kozhikode, Kerala, INDIA. ${ }^{3}$ Department of Psychiatry, lqraa International Hospital and Research Centre, Calicut, Kerala, INDIA.

${ }^{4}$ Department of Psychiatry, National Institute of Mental Health and Neurosciences, Bangalore, Karnataka, INDIA.
\end{abstract}

\section{Correspondence \\ Dr. N.A. Uvais, \\ Department of Psychiatry, Iqraa Inter- national Hospital and Research Centre, Calicut, Kerala-673009, INDIA \\ Phone no: +09562685573 \\ Email: druvaisna@gmail.com \\ History \\ - Submission Date: 16-09-2018. \\ - Revised Date: 15-11-2018; \\ - Accepted Date: 15-03-2019.}

DOI : 10.5530/ijmedph.2019.1.7

Article Available online

http://www.ijmedph.org/v9/i1

\section{Copyright}

(C) 2019 Phcog.Net. This is an openaccess article distributed under the terms of the Creative Commons Attribution 4.0 International license.

\begin{abstract}
Objectives: Dental illness and psychiatric illness are among the most prevalent health prob-lems all over the world. Evidence suggests that people with mental illness are more vulnerable to dental neglect and poor oral health. Health care professions including dentists are not im-mune to social prejudices and share the general public's attitude attributed to people with mental illness, affecting quality of care. The aim of the study was to determine the extent to which dental interns are formally prepared to care for patients with mental illness, by as-sessing their attitudes towards people with mental illness. Materials and Methods: Cross-sectional descriptive design was adopted for the present study. A total of 36 dental interns were purposively selected to complete self-reported questionnaires, which consist of four items to seek the background of the participants in the study, which include "age, gender, residence and contact with persons with mental illness" and, 34 item Opinion about mental illness for Chinese community (OMICC) scale. which is a valid and reliable, self-report meas-ure of attitudes. Results: Dental interns have significant positive attitudes towards mental illness in two of the six attitude factors: Benevolence $(30.58 \pm 3.14)$ and stereotyping $(5.61 \pm 1.02)$. However, they have negative attitudes in stigmatization $(10.08 \pm 3.02)$, separa-tism $(26.33 \pm 4.83)$, restrictiveness $(10.08 \pm 2.96)$ and pessimistic prediction $(13.47 \pm 3.61)$ do-mains as they rated high. Conclusion: The findings of the present study have important implica-tions for care of person with mental illness by dental interns and thereby on dental training. Thus, academic education from courses in this area must be planned so as to favour the change in the attitudes and promote a commitment to provide holistic care to people with mental illness.

Key words: Academic education, Attitudes, Mental illness, Dental interns.
\end{abstract}

\section{INTRODUCTION}

Negative prejudices and the cultural stereotypes of the general public affect mental health professionals and the mentally ill patients globally. ${ }^{1}$ Stigma and discrimination are the main obstacles facing the mentally ill today and it is the shame and fear of this discrimination that prevents the mentally ill from seeking help and care for their disorders. ${ }^{2}$ Research has shown that social prejudice and negative attitude towards mental illness exist even among health care professionals, affecting the quality and outcome of care for mentally ill.

Dental illness and psychiatric illness are among the most prevalent health problems all over the world. Evidence suggests that people with mental illness are more vulnerable to dental neglect and poor oral health. ${ }^{4}$ Increasing numbers of people with mental illness no longer live in institutions and they are dependent on dentists in private practice for care. A series of reports has emphasized that people with mental illness have limited access to oral health care. ${ }^{5}$ This problem begins in the dental schools, which are providing increasingly minimal didactic and clinical experience in how to care for people with mental illness and special needs. ${ }^{6}$ As a result, dental practitioners may be hesitant to treat these patients. We conducted a study to determine the extent to which dental interns are formally prepared to care for patients with mental illness, by assessing their attitudes towards people with mental illness.

\section{MATERIAL AND METHOD}

Study was conducted in a super speciality teaching hospital in Mangalore, India in from January to March 2015. e average number of interns at any point of time varies between 50-60 in this teaching hospital. Sampling was not done as the number of interns at any point in time was 50-60. A er explaining the research aims and methods, dental interns were invited to the study and verbal consent was taken. If they agreed to participate in the study, they were asked to complete the questionnaire by themselves. Questionnaire was distributed to all interns. However, only 36 responded. No participant had any special training for dealing with people with mental illness or special population. e data sheet consists of four items to seek the background of the participants in the study, which include "age, gender, residence and contact with persons with mental illness" and Attitude Scale for Mental Illness (ASMI), A modified version of the questionnaire, Opinion about Mental Illness for Chinese Community (OMICC) scale. OMICC scale, developed by $\mathrm{Ng}$ et al. on the basis of face valid- 
ity; building on the scale of Opinion about Mental Illness (OMI) with a small-scale survey among mental health professionals, contains 34 questions to assess six domains. ${ }^{7}$ Six domains studied are:

1) Benevolence, identified by items related to kindly orientation towards people with mental illness; 2) Separatism, characterized by items emphasized the distinctiveness of people with mental illness and to keep them away at a safe distance; 3 ) Stereotyping, defined by items that fixed people with mental illness in a particular behavioral pattern, mental ability and mannerism; 4) Restrictiveness, identified with items that held a doubtful view on the rights of people with mental illness; 5) Pessimistic prediction, derived from items that held a view that people with mental illness are unlikely to improve and that how society treats them is not optimistic; and 6) Stigmatization, identified from items that perceived mental illness as shameful, that sufferers should be kept from being known to others. Respondents were given the choice of five response categories to tick based on their feelings from strongly disagree to strongly agree (Strongly disagree $=1$, disagree $=2$, uncertain $=3$, agree $=4$, strongly agree $=5$ ) accordingly.

Factor analysis of the OMICC scale with 34 questions in "six" domains has been reported to yield a Cronbach's Alpha of 0.866 . $^{7}$

\section{Data Analysis}

For perception about mental illness, frequency distribution of the responses was calculated. Analysis of OMICC attitude scale was done like any other likert scale with five-point responses. All responses under each domain were coded from one to five and reverse coded for benevolence domain. Analysis was performed in the form of mean and standard deviation. Attitude in each domain was determined on the basis of pooled mean values for the respective domain. Values higher than "two" were consider as negative attitude in the respective questions.

Difference in attitude across age, place of residence and contact with person with mental illness in six domains was assessed by Spearman's Correlation. $P<0.05$ was considered statistically significant. Data analysis was done with SPSS version 17 for windows.

\section{RESULTS}

The final sample consisted of 36 participants with an age range of 21 to 27 years $($ Mean $[M]=22.53$, Standard Deviation $[S D]=1.20)$. Most of the participants came from urban and semi urban places ( $n=15$ each), followed by rural areas $(n=6) .8$ out of 36 participants had acquaintance of a close relative with mental illness.

Table 1 explains the responses (Mean scores) of the participants to the OMICC scale. High scores were observed in both the positive and negative domains of the scale as discussed below. However, higher scores on the negative domains of the scale indicated an overall unhealthy attitude of dental interns toward those with mental illness. Higher scores were observed on the positive domain of benevolence (30.58 \pm 3.14 ), but equally high scores were noted on other domains also, namely, Separatism (26.33 \pm 4.83$)$, Restrictiveness (10.08 \pm 2.96$)$ stigmatization (10.08 \pm 3.02$)$ and Pessimistic prediction (13.47 \pm 3.61$)$. However, less than cut-off point scores were observed in stereotyping (5.61 \pm 1.02$)$. Corrected mean was calculated as mean score of a subscale divided by total number of items in that subscale. As in Figure 1 corrected mean was highest for benevolence (3.82 \pm 0.39 ), pessimistic prediction (3.36 \pm 0.9$)$, separation $(2.63 \pm 0.48)$, stigmatization $(2.52 \pm 0.75)$, restrictiveness $(2.52 \pm 0.74)$ and stereotypic attitude $(1.4 \pm 0.3)$ in the same order.

No significant correlation was noted on age, place of residence and contact with relatives suffering from mental illness, with any of the OMICC scores (Table 2).

\section{DISCUSSION}

This study was novel in its attempt to examine the dental intern's attitudes toward mental illness. To the best of our knowledge, there are no studies in India investigating dental intern's attitudes towards mental illness.

The present study used a standardized questionnaire that measures the multiple dimensions, helping us to identify both the negative and positive aspects of the attitudes where we can work on to intervene, reinforce and enhance the attitudes of dental intern to provide proper care to persons with mental illness.

In the present study, the results showed that dental interns have significant positive attitudes toward mental illness in two of the six attitudes factors: Benevolence and Stereotyping. These findings can be compared with a past study among medical students, where the researcher concluded that medical students had unhealthy attitudes in all domains except in Benevolence domain. ${ }^{8}$ Another study exploring dentistry students's views about mental illness and impact of a targeted seminar on knowledge and attitudes found that they understood mental disorder broadly, employing diverse causal models and the attitudes were benevolent and most students reported willingness to provide dental care to affected individuals. ${ }^{9}$

Higher benevolence scores among participants indicated that most of them would express kindness and altruism toward the person suffering from any form of mental illness. ${ }^{10}$ The participants showed less stereotyping attitude toward mentally ill as they rated low to the statements

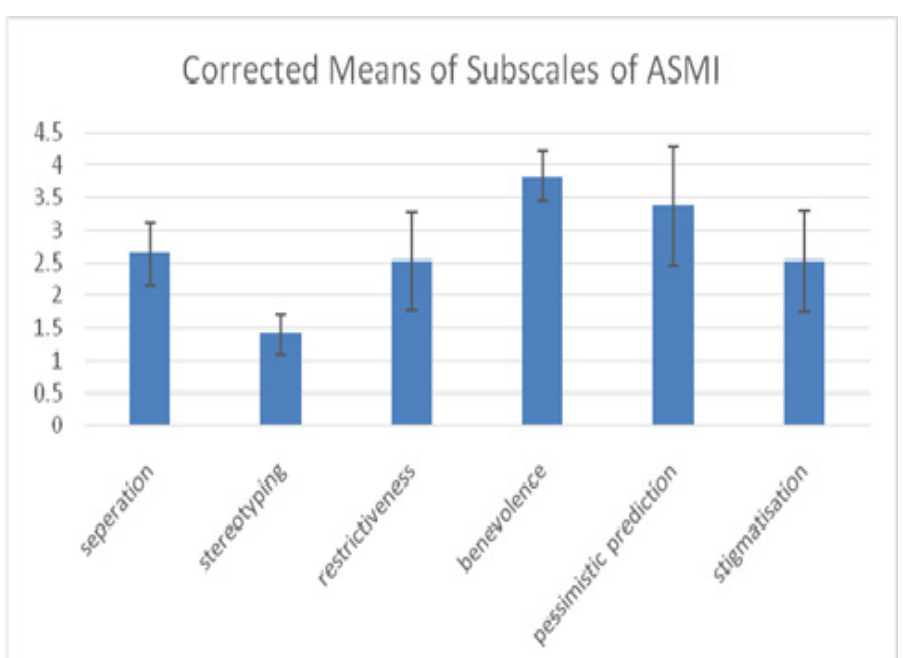

Figure 1: Corrected Means of Subscales of ASMI

\begin{tabular}{|c|c|c|c|c|c|}
\hline Subscales & $\begin{array}{l}\text { No. of } \\
\text { items }\end{array}$ & $\begin{array}{l}\text { Possible } \\
\text { score }\end{array}$ & $\begin{array}{c}\text { Cut-off } \\
\text { (mid) } \\
\text { point }\end{array}$ & Mean & $\begin{array}{l}\text { Standard } \\
\text { deviation }\end{array}$ \\
\hline Separatism (S) & 10 & $5-50$ & 25 & 26.33 & 4.8 \\
\hline Stereotyping (St) & 4 & $4-20$ & 10 & 5.61 & 1.20 \\
\hline Restrictiveness (R) & 4 & $4-20$ & 10 & 10.08 & 2.96 \\
\hline Benevolence (B) & 8 & $8-40$ & 20 & 30.58 & 3.14 \\
\hline $\begin{array}{c}\text { Pessimistic } \\
\text { prediction }(\mathrm{P})\end{array}$ & 4 & $4-20$ & 10 & 13.47 & 3.61 \\
\hline $\begin{array}{l}\text { Stigmatization } \\
\text { (Stig) }\end{array}$ & 4 & $4-20$ & 10 & 10.08 & 3.02 \\
\hline
\end{tabular}




\begin{tabular}{|c|c|c|c|c|c|c|}
\hline & seperation & stereotyping & restrictiveness & benevolence & $\begin{array}{l}\text { pessimistic } \\
\text { prediction }\end{array}$ & stigmatisation \\
\hline Age & -.027 & .083 & .035 & -.082 & -.142 & .044 \\
\hline Place of residence & -.137 & .327 & -.187 & -.110 & -.144 & .120 \\
\hline $\begin{array}{l}\text { Contact with person } \\
\text { with mental illness }\end{array}$ & -.019 & -.127 & -.052 & -.046 & -.107 & .032 \\
\hline
\end{tabular}

None of the correlation co-efficient was statistically significant at $p=0.05$

in stereotyping domain, indicating stereotypes about mental illness like influence of evil spirits, religious afflictions and deviation from societal norms were not considered by most of them.

However, dental interns had negative attitudes in separatism, stigmatization, restrictiveness and pessimistic predictions domains as they rated high. Higher separatism scores meant a negative attitude when it came to accepting the autonomy and independence of the mentally ill and in considering them as part of the larger unaffected community. Stigmatization is the phenomenon whereby an individual with an attribute, such as mental illness, which is deeply discredited by his/her society, gets rejected as a result of the same and was also rated high. ${ }^{11}$ High scores in pessimistic prediction scores indicate the lack of concept of partial recovery, rehabilitation of mentally ill patients, among the respondents. ${ }^{12}$ High scores on the restrictiveness domain indicate that mentally ill people cannot enjoy personal or social life events such as marriage, working, having children, or family. ${ }^{13}$

In a nutshell, the present study showed the dental interns have significant positive attitudes toward mental illness in two of the six attitudes factors: benevolence and stereotyping. However, they have negative attitudes in separatism, stigmatization, restrictiveness and pessimistic predictions domains as they rated high. Studies done among medical students and nursing students reported that they had more positive attitude towards patients with mental illness. ${ }^{14}$ The reason for having such a positive attitude is thought to be due to their knowledge about mental health and illness, skills they acquire while training in dealing with challenging behaviours shown by patients with mental illness and contact with mental illness. ${ }^{14}$ Studies have shown that contact with patients with mental illness and taking courses on mental illness leads to less stigmatising attitude. ${ }^{15}$ The negative attitude seen among the study sample may be due to lack of exposure to patients with mental illness during their course and lack of knowledge about mental health and illnesses.

These findings have important implications for care of person with mental illness and thereby on dental training. Thus, academic education from courses in this area must be planned so as to favour the change in the attitudes that include greater use of teaching strategies that challenge beliefs and assumptions and promote a commitment to provide holistic care to people with mental illness.

The limitations of the present study were small sample size, all women interns and the lack of a qualitative component. Moreover, there was a self-selection bias. The results pertain to those who participated in the study and not all interns. Therefore, the results are not generalisable. Future studies in larger samples, including both gender, conducted in different socio-cultural settings, using both qualitative and quantitative methods, are needed to shed more light on the attitude of dental interns towards patients with mental illness.

\section{CONCLUSION}

Our study explored the extent to which dental interns are formally prepared to care for patients with mental illness, by assessing their attitudes towards people with mental illness. We found that dental interns have significant positive attitudes towards mental illness in two of the six attitude factors. The findings of the present study have important implications for care of person with mental illness by dental interns and thereby on dental training

\section{ACKNOWLEDGEMENT}

None

\section{CONFLICT OF INTEREST}

The authors no conflict of interest.

\section{REFERENCES}

1. Emrich K, Thompson TC, Moore G. Positive attitude. An essential element for effective care of people with mental illnesses. J Psychosoc Nurs Ment Health Serv. 2003;41(5):18-25

2. British Society for Disability and Oral Health. Oral health care report for people with mental health problems guidelines and recommendations. Report of the BSDH Working Group. 2000.

3. Gowda E, Bhat $P$, Swamy M. Dental health requirements for psychiatric patients. MJAFI. 2007;63(4):328-30

4. McCreadie R, Stevens H, Henderson J, Hall D, McCaul R, Filik R, et al. The dental health of people with schizophrenia. Acta Psychiatr Scand. 2004;110(4):30610.

5. Purandare N, Woods E, Butler S, Morris J, Vernon M, McCord JF, et al. Dental health of community-living older people attending secondary healthcare: a cross-sectional comparison between those with and without diagnosed mental illness. Int Psychogeriatr. 2010;22(3):417-25.

6. Cormac I, Jenkins P. Understanding the importance of oral health in psychiatric patients. Adv Psychiatr Treat. 1999;5(1):53-60.

7. Ng P, Chan KF. Sex differences in opinion towards mental illness of secondary school students in Hong Kong. Int J Soc Psychiatry. 2000;46(2):79-88.

8. Lingeswaran A. Psychiatric curriculum and its impact on the attitude of Indian undergraduate medical students and interns. Indian J Psychol Med. 2010;32(2):119-27.

9. Patterson S, Ford P. Dentistry students' views about mental illness and impact of a targeted seminar on knowledge and attitudes: A mixed-method study. J MentHealth Training, Education and Practice. 2014;9(3):190-202.

10. DeAvanci RC, Malaguti SE, Pedrão LJ. Authoritarianism and benevolence towards mental illness: Study with beginning a nursing program. Rev Lat Am Enfermagem. 2002;10(4):509-15.

11. Byrne P. Stigma of mental illness and ways of diminishing it. Adv Psychiatr Treat. 2000;6(1):65-72

12. Pedrão LJ, Avanci Rde C, Malaguti SE. Profile of undergraduate nursing students' attitudes towards mental disease, before the influence of specific academic education. Rev Lat Am Enfermagem. 2002;10:794-9.

13. Hinkelman L, Granello DH. Biological sex, adherence to traditional gender roles and attitudes toward persons with mental illness: An exploratory investigation. J Ment Health Couns. 2003;25:259-70.

14. Tork HMM, Abdel-Fattah AES. Female students' attitude toward mental Illness in Qassim university, KSA. American Journal of Nursing Science. 2015;4(3):5056. doi: 10.11648/j.ajns.20150403.12

15. Poreddi V, Reddy D, Math S, Thimmaiah R. Attitudes of undergraduates towards mental illness: A comparison between nursing and business management students in India. South Africa Journal of psychology. 2013;19(3):66-73.

Cite this article : Rasmina V, Hafeeq B, Uvais NA, Sreeraj VS. Attitudes of Dental Interns Towards Mental Illness. Int J Med Public Health. 2019;9(1):28-30. 